\title{
Envolvimento do glutamato na ansiedade de ratos no labirinto em cruz elevado'
}

\author{
Camila Pinheiro Pozzer ${ }^{2}$ \\ Ivaldo Jesus Lima de Oliveira ${ }^{3}$
}

\section{Resumo}

O glutamato (GLU) é o neurotransmissor excitatório mais importante existente no cérebro do homem e interfere no processo da ansiedade. Os receptores do (GLU) são ionotrópicos (NMDA, AMPA e cainato) e metabotrópicos (acoplados às proteínas G). Investigou-se o envolvimento do (GLU) sobre os níveis de ansiedade de ratos submetidos ao (LCE) para detectar a dose mais eficaz e o efeito do glutamato (ansiolítico ou ansiogênico), por meio de uma curva dose-resposta. Realizaram-se experimentos com ratos Wistars machos de (200 a 280g). As porcentagens de tempo gasto nos braços abertos foram consideradas indicadores de ansiedade. As doses de (GLU), 3 e 5 mg/kg (i.p.), apresentaram efeito ansiogênico sobre a ansiedade destes animais. Esses resultados demonstraram que as porcentagens de tempo nos braços abertos dos animais experimentais diminuíram em relação ao grupo controle e com maior efetividade detectada com a dose de $3 \mathrm{mg} / \mathrm{kg}$ (i.p).

Palavras-chave: Glutamato. Receptores ionotrópicos. Ansiedade. Labirinto em cruz elevado.

\section{Introdução}

Compreender a transmissão do glutamato no sistema nervoso central (SNC) dos humanos é de extrema relevância para o entendimento da neurobiologia dos

\footnotetext{
${ }^{1}$ Esta pesquisa foi realizada no Programa de Iniciação Científica do Centro Universitário de Brasília (UniCEUB) como parte integrante do relatório realizado e defendido na Faculdade de Ciências da Saúde em 2007.

${ }^{2}$ Camila Pinheiro Pozzer foi bolsista do Programa de Iniciação Científica do UniCEUB e está no último ano do curso de Psicologia.

${ }^{3}$ Ivaldo Jesus Lima de Oliveira possui graduação em Biologia pelo UniCEUB (1993) e mestrado em Neurociências pela Universidade Federal de Santa Catarina (2001). É professor titular do UniCEUB e professor classe A da Secretaria de Estado de Educação.
} 
transtornos mentais para a criação de novos psicofármacos que auxiliem no atendimento dessas pessoas. O interesse pela invenção de compostos que apresentam glutamato justifica-se pelo uso na clínica médica de compostos que possuem fortes efeitos colaterais, o que dificulta a adesão dos pacientes ao tratamento com esses psicofármacos. Assim, os compostos glutamatérgicos auxiliariam na intervenção imediata dos médicos, pois não geram dependência nos pacientes e também não possuem efeitos sedativos.

O glutamato está envolvido em vários processos bioquímicos, dentre eles: (1) metabolismo energético, (2) síntese de ácidos graxos, (3) regulação dos níveis de amônia; e (4) composição de proteínas e peptídeos, bem como em funções cerebrais: (a) desenvolvimento neural, migração e diferenciação celular, (b) plasticidade sináptica, cognição, controle motor, aprendizagem e memória, (c) precursor do ácido gama aminobutírico (GABA) em sinapses inibitórias (CARLSON, 2002).

Além de ser o principal neurotransmissor excitatório do sistema nervoso central de mamíferos, suas ações excitatórias são conhecidas desde os anos 50. Experimentos realizados ao longo dos últimos anos têm comprovado o seu envolvimento com o desenvolvimento neural, plasticidade sináptica, aprendizado, memória, dano neuronal pós-isquemia ou hipoglicemia, dependência e tolerância a drogas, dor neuropática, epilepsia e outras doenças neurodegenerativas (Alzheimer, Parkinson, Huntington e esclerose amiotrófica lateral), além da ansiedade e depressão (CAROBREZ, 2003).

Segundo Tortora e Grabowski (2002), o glutamato é um aminoácido excitatório largamente usado no sistema nervoso central, sendo o neurotransmissor excitatório mais abundante nesse sistema. Cerca de 75\% da atividade excitatória do cérebro depende do glutamato, daí a importância de pesquisá-lo. Ele participa de alterações na transmissão sináptica (comunicação entre neurônios) e é o responsável pela memória e aprendizagem, sendo que a função do glutamato como neurotransmissor é comprovada pelos seguintes fatores: sua localização neuronal, existência de sua recaptação de alta afinidade, liberação cálcio-dependente que evoca resposta pós-sináptica e identidade farmacológica entre o glutamato exógeno aplicado e o neurotransmissor natural do SNC (sistema nervoso central). 
O glutamato, conforme Oliveira (1994), está ligado à plasticidade do cérebro, ou seja, à capacidade do cérebro em reaprender habilidades mentais e físicas após lesão ou para se ajustar a uma nova circunstância. Esse neurotransmissor age estimulando o receptor em determinadas células que contêm uma proteína conhecida como receptor NMDA, o qual fortalece ou reforça os circuitos neurais entre as células nervosas que armazenam a memória.

Os receptores de glutamato são classificados em duas categorias distintas, de acordo com suas propriedades farmacológicas e funcionais: os receptores ionotrópicos e os metabotrópicos. Os receptores ionotrópicos (iGluRs) são assim denominados porque abrem canais cátion-específicos e são subdivididos de acordo com a especificidade da ação de seus análogos sintéticos mais seletivos: N-metil-D-aspartato (NMDA), ácido-amino-3-hidróxi-5-metil-4-isoxazol propiônico (AMPA) e ácido Caínico (KA), conforme Carobrez (2003).

De acordo com Graeff (2001), dentre os receptores do glutamato que são canais dependentes de interação com ligantes externos, três tipos são identificados, baseando-se na potência com que respondem a diferentes análogos do glutamato. Eles são os receptores tipo cainato, AMPA, NMDA. Os receptores tipo KA e AMPA são canais catiônicos que promovem influxo de $\mathrm{Na}+$ e efluxo de $\mathrm{K}+$, o que mostra que esses receptores AMPA e KA são permeáveis a $\mathrm{Na}^{+}$ e $\mathrm{K}^{+}$e são responsáveis pela rápida ativação da neurotransmissão excitatória no sistema nervoso central. Os receptores tipo NMDA são canais iônicos cuja ativação pelo glutamato depende de uma co-ativação da glicina. No nível do potencial de membrana normal, o canal é bloqueado por um íon $\mathrm{Mg} 2+$, sendo desbloqueado, apenas, quando a membrana é parcialmente despolarizada.

Segundo Carobrez (2003), os comportamentos defensivos fazem parte da ansiedade do animal como uma reação a um perigo potencial ou presente. Quando há a detecção de um perigo, conexões neurais são ativadas por meio do glutamato para reter informações e facilitar o aprendizado em relação ao perigo detectado. Nesse sentido, os transtornos de ansiedade estão relacionados a uma falha na detecção do perigo e a uma alteração na reação de defesa. O efeito do aminoácido excitatório (GLU) é o de evocar reações de defesa do animal. 
Em geral, considera-se o medo como provocado por estímulo ou situação bem definidos. Já a ansiedade, ao contrário, teria causas difíceis de especificar. A emoção da ansiedade é experimentada como normal se for adequada às circunstâncias e aceita como um acontecimento que acompanha naturalmente o estímulo necessário para lidar com uma situação específica. A ansiedade é um termo geral para descrever a preocupação ou antecipação de eventos futuros envolvendo perigo ou infortúnio. Ela é acompanhada por sensações desagradáveis ou sintomas físicos de tensão (HETEM; GRAEFF, 2004).

A ansiedade passa a ser patológica, quando é desproporcional à situação que a desencadeia, quando não existe um objeto específico ao qual se direcione, ou quando os níveis de funcionamento do indivíduo ansioso se tornam de tal forma que já não há resposta adequada às tensões do dia-adia, do trabalho ou outros estímulos, e por isso, faz-se necessário também refletir sobre a ansiedade relacionada aos problemas causados pelas pressões da vida contemporânea, por exemplo, o estresse, em que repetidos momentos de ansiedade vêm indicando altos níveis de estresse (HETEM; GRAEFF, 2004).

Quando um animal é confrontado com uma ameaça à sua sobrevivência ou à sua integridade física ele apresentará um conjunto de respostas comportamentais como luta (reage à situação), fuga (foge da ameaça) ou congelamento (pára, estaciona) e um conjunto de respostas neurovegetativas, como o aumento do fluxo sangüíneo para a musculatura esquelética, aumento da freqüência cardíaca, aumento da ventilação pulmonar, elevação da pressão sangüínea, defecação, micção etc, devido à intensa ativação do sistema nervoso simpático (HETEM; GRAEFF, 2004).

A partir desse aporte teórico explicitado, essa pesquisa investigou o efeito do glutamato (GLU) sobre os níveis de ansiedade em ratos que posteriormente podem ser avaliados em testes pré-clínicos, desenvolvendo fármacos mais seletivos para os receptores de glutamato, visando melhorar a vida de diversas pessoas que sofrem de ansiedade. Sendo assim, este trabalho pretendeu responder à seguinte pergunta: Qual seria o efeito do glutamato (GLU) sobre os níveis de ansiedade de ratos submetidos ao labirinto em cruz elevado? 


\section{Material e Métodos}

Investigou-se o efeito do glutamato (GLU) sobre os níveis de ansiedade de ratos submetidos ao labirinto em cruz elevado (LCE) por 5 minutos, nas doses crescentes (1, 3, 5 e $10 \mathrm{mg} / \mathrm{Kg}$, i.p) (1,0 ml/kg), com a finalidade de detectar a dose mais efetiva, por meio de uma curva dose-resposta, avaliando assim se o efeito do glutamato é ansiolítico ou ansiogênico.

Em cada experimento, foram utilizados 5 ratos Wistars machos de 200 a 280 gramas provenientes do Biotério Central do UniCEUB. Os ratos foram mantidos em condições de livre acesso à comida e à água, sob um ciclo claro-escuro de 12 horas. Cada animal foi ingênuo às drogas e foi usado somente uma vez. Os experimentos foram realizados na fase clara do ciclo, entre $14 \mathrm{~h} 00$ e 17h00. A temperatura foi controlada em $25 \pm 1{ }^{\circ} \mathrm{C}$. Todos os experimentos foram conduzidos de acordo com o padrão internacional de bem-estar de animais recomendado pela Sociedade Brasiliense de Neurociências e Comportamento (1992), bem como autorizado pelo Comitê de Ética do Centro Universitário de Brasília -UniCEUB.

O Labirinto em Cruz Elevado (LCE) (Figura 1) foi o equipamento utilizado nesta pesquisa, sendo de propriedade do laboratório do UniCEUB e que segue as especificações de Pellow et al (1985), sendo formado por 2 braços abertos e opostos (50 X $10 \mathrm{~cm}$ cada um), sendo cruzados por 2 braços do mesmo tamanho formando uma cruz. Os braços fechados estão cercados por paredes laterais de 50 $\mathrm{cm}$ de altura, exceto para a entrada, delimitando uma plataforma central de 10 x 10 $\mathrm{cm}$. Uma borda de acrílico transparente de $0.5 \mathrm{~cm}$ de altura está colocada ao longo das bordas dos braços abertos. Uma lâmpada vermelha (60 W), colocada a $120 \mathrm{~cm}$ de altura do labirinto, serve de iluminação. Este aparato de madeira foi colocado dentro de um cubículo experimental com isolamento acústico ideal (cabine do laboratório de psicobiologia do UniCEUB).

Na execução desta pesquisa, foram realizados 6 (seis) experimentos durante os meses de novembro e de dezembro de 2006, com continuidade de mais 6 (seis) experimentos nos meses de fevereiro a maio de 2007. Já as atividades de pesquisa documental tiveram início, em agosto de 2006, e continuaram até o mês de julho, com o encerramento do $5^{\circ} \mathrm{PIC}$, conforme o Edital do Programa de Iniciação Científica 2006. 


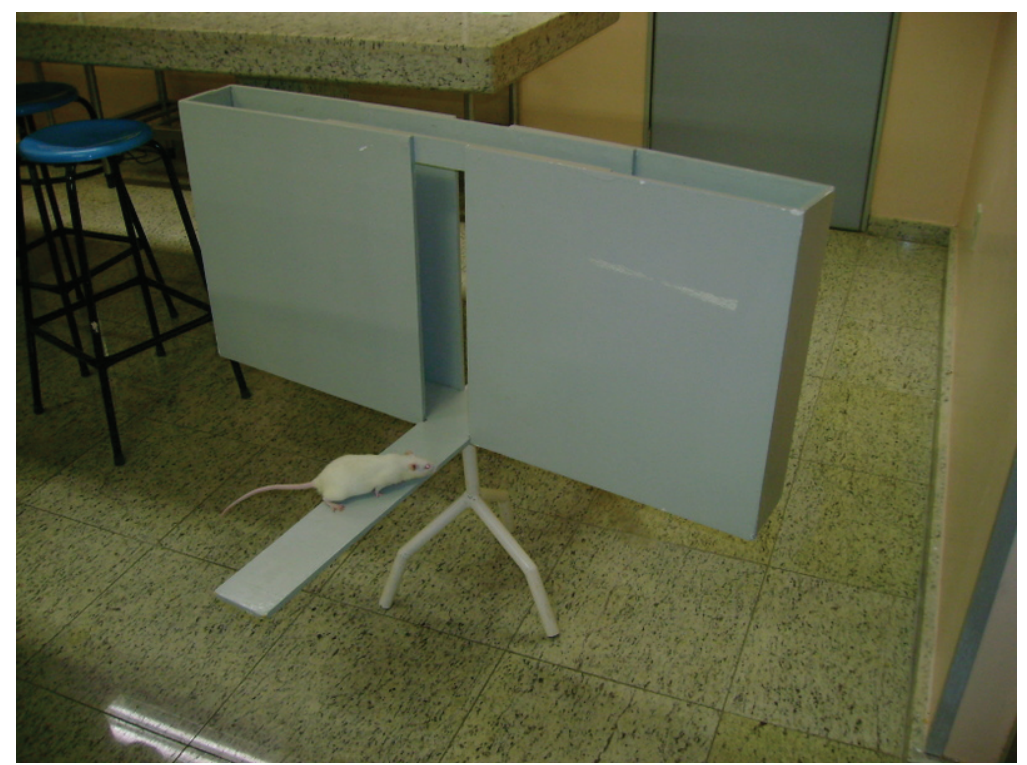

Figura 1 - Labirinto em Cruz Elevado (LCE)

Foram avaliados o tempo de permanência dos ratos nos braços abertos e o tempo de permanência nos braços fechados do labirinto, bem como a freqüência de permanência nas extremidades dos braços abertos e fechados, e no centro do labirinto, e também se registrou a quantidade de fezes eliminadas pelos animais no momento do teste no labirinto em cruz elevado.

Realizaram-se experimentos com ratos Wistar machos de 200 a 280 gramas. Os animais foram distribuídos em dois grupos: controle e experimental. Os animais controle receberam administração de solução salina e os experimentais receberam as doses crescentes de (GLU) (1, 3, 5 e $10 \mathrm{mg} / \mathrm{kg}$, i.p. com um volume de $1 \mathrm{ml} / \mathrm{kg}$ ), 30 minutos antes do teste no (LCE).

Após este período, os animais foram submetidos ao labirinto em cruz elevado (LCE) por 5 minutos e foram coletados os dados do tempo de latência nos braços abertos e fechados do (LCE), a quantidade de fezes eliminadas pelos animais durante o teste do (LCE), bem como foram calculadas as porcentagens de tempo gasto dos animais nos braços abertos e fechados do (LCE) registrados em tabelas e conduzidos à análise estatística. 


\section{Resultados}

Os dados obtidos foram submetidos à análise de variância de uma via (One Way ANOVA), apresentando um valor de $\mathrm{p} \leq 0,05$ considerado estatisticamente significativo e que foi indicado pelos grupos 3 e $5 \mathrm{mg} / \mathrm{kg}$, em relação ao grupo controle, pois o grupo controle apresentou $35,83 \pm 13,68$, enquanto os animais experimentais obtiveram $1(24,13 \pm$ $15,48) ; 3(11,99 \pm 8,50) ; 5(18,44 \pm 12,67)$ e $10(22,05 \pm 15,34)$ como porcentagens do tempo nos braços abertos do (LCE).

O Gráfico 1 apresenta as porcentagens do tempo gasto nos braços abertos do (LCE), indicando que a administração sistêmica de glutamato apresentou um efeito ansiogênico.

Esses resultados demonstraram que as porcentagens do tempo nos braços abertos dos animais experimentais diminuíram em relação ao grupo controle. Além disso, a maior efetividade detectada foi com a dose de (3 mg/kg i.p), sendo, portanto, esta dose mais eficiente em relação às demais (1, 5 e $10 \mathrm{mg} / \mathrm{kg}$ i.p.), descrevendo uma curva-dose resposta com o pico máximo de efeito para o glutamato, típica da experimentação com drogas psicofarmacológicas, que tende a aumentar o efeito até atingir o pico máximo e depois regredir gradualmente, conforme ficou demonstrado nesta pesquisa.

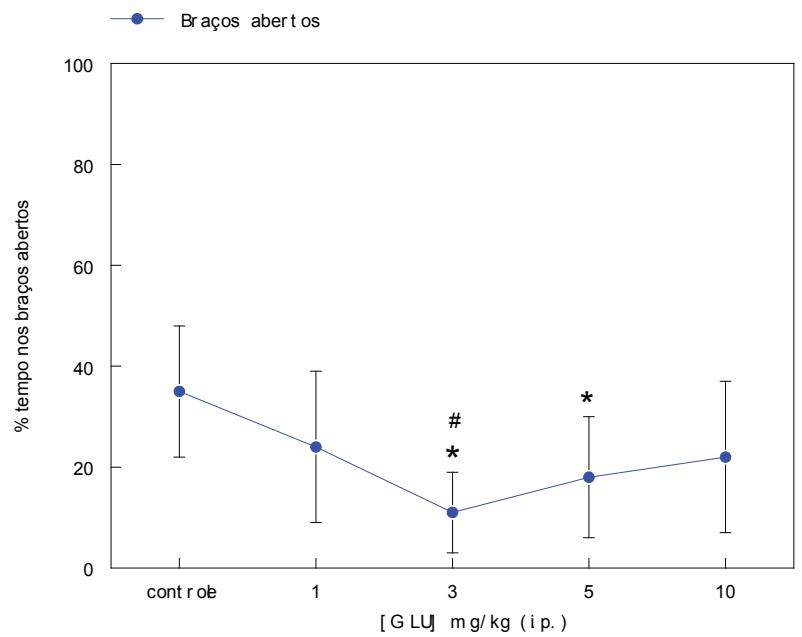

Gráfico 1 - Efeito da curva dose-resposta de glutamato sobre a ansiedade de ratos submetidos ao (LCE) por 5 minutos. Porcentagem média ( \pm EPM) do tempo gasto nos braços abertos entre os grupos injetados sistemicamente $(1,0 \mathrm{ml} / \mathrm{kg}$, i.p.) com solução salina ou glutamato nas doses de 1,3,5 e $10 \mathrm{mg} / \mathrm{kg}$ (i.p.). Asteriscos (*) indicam diferenças estatisticamente significativas ao nível de $\mathrm{p} \leq 0,05$. Sustenido (\#) significa a dose mais efetiva do glutamato 


\section{Considerações finais}

A literatura tem indicado que vários sistemas neurais estão envolvidos com o fenômeno da ansiedade, as investigações não se encerram e as perspectivas futuras são promissoras, pois novas abordagens têm sido desenvolvidas para o tratamento farmacológico da ansiedade no que se refere a sua relação com a transmissão glutamatérgica.

Neste estudo, portanto, avaliaram-se mecanismos neurais desencadeados pelo glutamato nos níveis de ansiedade, buscando novos fármacos que promovam a melhora da ansiedade e tenham menos efeitos colaterais. Sendo assim, nas próximas investigações verificar-se-ão efeitos de agentes antagonistas de glutamato que possam reverter este efeito ansiogênico detectado neste $5^{\circ} \mathrm{PIC}$, propiciando o bloqueio de seus receptores. Uma perspectiva futura para pesquisas nos próximos Programas de Iniciação Científica do UniCEUB pretende investigar a ação do ácido ascórbico e o guanosina-5' -monofosfato (GMP). Desta forma, as pesquisas devem prosperar na identificação de compostos com efeitos ansiolíticos para comercialização nas indústrias farmacêuticas e como conseqüência melhorar a vida de pessoas que sofrem com a ansiedade.

\section{Involvement of glutamate in anxiety levels of rats on the elevated plus-maze}

\section{Abstract}

Glutamate (GLU) is the most important excitatory neurotransmitter existent in the human brain, interfering in processe of anxiety. The (GLU) receptors are ionotropic (NMDA, AMPA and kainite) and metabotropic (coupled to G proteins). Investigated the involvement of (GLU) on the levels of anxiety in rats submitted the (EPM) for detect the most efficient dose and glutamate effect (anxiolythic or ansiogenic), through a dose-response curve. Experiments were realized with male Wistar rats (weighing form 200 to 280 grams). The percentage of time spent in the open arms was considered as an indicator of anxiety. The (GLU) doses of $\mathbf{3}$ and $5 \mathrm{mg}$ per $\mathrm{kg}$, indicared that the (GLU) have presented ansiogenic effect over the animals. These results demonstrated that the percentages of time spent on the open 
arms by the animals from the experimental group were indeed less, when related and compared to those spent by the control group, detecting higher effectiveness with a dose of $3 \mathrm{mg}$ per kilo.

Key words: Glutamate. Ionotropic receptors. Anxiety. Elevated plus-maze.

\section{Referências}

CARLSON, N. R. Fisiologia do comportamento. São Paulo: Manole, 2002.

CAROBREZ, A. P. Transmissão pelo glutamato como alvo molecular na ansiedade. Revista Brasileira de Psiquiatria, São Paulo, v. 25, n. 2, p. 52-58, 2003.

HETEM, L. A. B.; GRAEFF, F. G. Transtornos de ansiedade. São Paulo: Atheneu, 2004.

OLIVEIRA, I. R. Manual de psicofarmacologia clínica. Rio de Janeiro: Medsi, 1994.

PELLOW, S. et. al. Validation of open: closed arms entries in the elevated plus maze as a measure of anxiety in the rat. Pharmacology Biochemistry and Behavior, [S.1.], n. 24, p. 525-529, 1985.

TORTORA, G. J.; GRABOWSKI, S. R. Princípios de anatomia e fisiologia. Rio de Janeiro: Guanabara, 2002. 
